\title{
DESEMPENHO DE BOMBA CENTRÍFUGA OPERANDO COM ÁGUA RESIDUÁRIA DO PROCESSAMENTO DO CAFÉ ${ }^{1}$
}

\section{JACINTO A. CARVALHO ${ }^{2}$, REINALDO F. AQUINO ${ }^{3}$, GERALDO M. PEREIRA ${ }^{4}$, REGINALDO C. RODRIGUES ${ }^{5}$, THIAGO B. CAMPOS ${ }^{5}$}

\begin{abstract}
RESUMO: Este trabalho foi desenvolvido com o objetivo de avaliar o desempenho de bomba centrífuga no recalque de águas residuárias provenientes do processamento do café, especificamente do descascamento e da demucilagem. Montou-se uma bancada, composta por caixas d'água, tubulações, válvulas, medidores de vazão e de pressão, e uma motobomba para a realização dos ensaios. Esses consistiram em aberturas parciais do registro, na saída da bomba, e medições da vazão e da pressão desenvolvida, e da energia consumida. Tais procedimentos foram realizados, primeiro, utilizando água pura, e depois com águas residuárias, em suas concentrações originais e com diversos graus de diluições. Os ensaios mostraram quedas acentuadas de altura manométrica e de rendimento, e aumento da potência demandada com a vazão recalcada de água residuária em comparação ao desempenho da mesma bomba operando com água limpa; a diluição das águas residuárias promoveu melhor desempenho da bomba em relação àquela com concentração original.
\end{abstract}

PALAVRAS-CHAVE: bomba hidráulica, rendimento, potência.

\section{CENTRIFUGAL PUMP PERFORMANCE USING COFFEE PROCESS WASTEWATER}

ABSTRACT: This work was carried out to evaluate the performance of a centrifugal pump operating with wastewater from coffee process. Under laboratory conditions, it was determined the hydraulic characteristics (manometric height, engine power and efficiency) for a centrifugal pump, operating with clear water and coffee process wastewater. The results have show that manometric height and efficiency was smaller and the engine power was higher when the coffee process wastewater was used in comparison with results obtained for clean water. The smaller the concentration of that coffee wastewater produced the better the performance of the pump in comparison with the performance obtained with original concentration of the coffee wastewater.

KEYWORDS: hydraulic pump, efficiency, power.

\section{INTRODUÇÃO}

O café é uma das maiores fontes de renda da agricultura brasileira e uma das mais importantes culturas de exportação do País. As áreas produtoras de café no Brasil estão distribuídas principalmente na região Centro-Sul (Minas Gerais, São Paulo, Espírito Santo e Paraná). O sul de Minas Gerais, além de produzir $25 \%$ do café brasileiro, é responsável pela produção de cafés de excelente qualidade, devido as suas condições de clima e solo favoráveis ao desenvolvimento da cultura.

A atividade de lavagem e de despolpa de frutos do cafeeiro, necessária na redução do custo da secagem dos grãos e na melhoria na qualidade da bebida, é geradora de grandes volumes de águas residuárias, ricas em material orgânico em suspensão e constituintes orgânicos e inorgânicos em solução. Devido ao elevado poder poluente que essas águas detêm, torna-se inadmissível o seu lançamento, sem tratamento, em corpos hídricos.

\footnotetext{
${ }^{1}$ Trabalho financiado pelo Consórcio Brasileiro de Pesquisa e Desenvolvimento do Café.

${ }^{2}$ Prof. Associado, DEG/UFLA, Lavras - MG, Fone: (0XX35) 3829.1489, jacintoc@ufla.br

${ }^{3}$ Doutorando em Engenharia Agrícola, UFLA, Lavras - MG.

${ }^{4}$ Prof. Associado, DEG/UFLA, Lavras - MG, Fone (0XX35) 3829.1389, geraldop@ufla.br

${ }^{5}$ Graduando em Engenharia Agrícola, UFLA, Lavras - MG

Recebido pelo Conselho Editorial em: 19-12-2006

Aprovado pelo Conselho Editorial em: 29-1-2008
} 
Segundo ZULUAGA et al. (1991), citados por CAMPOS et al. (2003), um balanço de massa e a determinação da capacidade contaminante dos produtos gerados no processo úmido do café permitem observar que a polpa proveniente da despolpa a seco de $1 \mathrm{~kg}$ de café em cereja tem capacidade contaminante equivalente a 1,3 habitante dia $^{-1}$. Quando essa polpa é transportada hidraulicamente, na taxa de 1,08 L de água por $\mathrm{kg}$ de café cereja, a quantidade de matéria orgânica transmitida para a água tem capacidade de contaminação igual a 0,5 habitante dia $^{-1}$. CAMPOS et al. (2003) citam que, na Colômbia, por exemplo, nos últimos anos, com produção média anual de 12 milhões de sacas de $60 \mathrm{~kg}$ (720 mil toneladas), foram geradas 351 mil toneladas de matéria seca. Isso corresponde à carga poluidora similar à de uma população de 20 milhões de habitantes.

A Legislação Ambiental do Estado de Minas Gerais (Deliberação Normativa COPAM n ${ }^{\circ}$ 10/86) estabelece que, para o lançamento de águas residuárias em corpos hídricos, a Demanda Bioquímica de Oxigênio $\left(\mathrm{DBO}_{5}, 20^{\circ} \mathrm{C}\right.$ ) seja inferior a $60 \mathrm{mg} \mathrm{L}^{-1}$ (CAMPOS et al., 2003). Por meio de análises conduzidas no Laboratório de Análise de Água do Departamento de Engenharia LAADEG/UFLA, constatou-se que a água residuária proveniente da lavagem e da despolpa do café gerou DBO média em torno de $6.000 \mathrm{mg} \mathrm{L}^{-1}$, valor bem acima do permitido pela Legislação Ambiental para lançamento de efluentes líquidos em corpos hídricos.

Logo, é fácil perceber que a utilização de águas residuárias em lavouras ou para tratamento resulta em importantes contribuições para a melhoria dos recursos hídricos da região, como: redução do volume de água captada em rios ou lagos para fins de irrigação e minimização da poluição pela redução do lançamento de águas residuárias nos mananciais hídricos.

A utilização de águas residuárias para a irrigação ou tratamento deverá consistir em fator econômico fundamental para o produtor, já que a água captada em lagos e rios passará a ser taxada, de acordo com a nova legislação sobre o uso da água em todos os Estados brasileiros. Entretanto, projetos de irrigação ou de tratamento de águas residuárias requerem dados técnicos referentes à situação encontrada na prática. O tipo de fluido e, conseqüentemente, a sua perda de carga em tubulações são fundamentais no dimensionamento das tubulações e das bombas desses sistemas, uma vez que a altura manométrica representa a energia fornecida ao líquido suficiente para vencer o desnível geométrico e as perdas de carga ocorridas ao longo do percurso.

As características hidráulicas do escoamento de águas residuárias nas tubulações são praticamente desconhecidas, podendo levar técnicos a cometerem erros consideráveis no dimensionamento de sistemas de bombeamento. Existem poucos trabalhos que abordam detalhadamente o assunto, provavelmente devido ao grau de complexidade envolvido, por se tratar de um fluido com comportamento diferente da água.

De acordo com TEIXEIRA (1973), alterações na natureza da água podem causar modificações no desempenho das bombas, sendo, portanto, de fundamental importância 0 conhecimento das novas curvas de desempenho dessas bombas, para que o seu uso possa ser feito dentro de condições ideais de funcionamento. Nesse contexto, o presente trabalho teve como objetivo avaliar o desempenho de motobomba operando com água residuária proveniente do descascamento e da demucilagem do café, e com as diluições dessas.

\section{MATERIAL E MÉTODOS}

O trabalho foi conduzido na Área Experimental de Hidráulica, setor de Engenharia de Água e Solo, do Departamento de Engenharia, da Universidade Federal de Lavras (Lavras, sul de Minas Gerais, altitude média de $910 \mathrm{~m}, 21^{\circ} 14^{\prime} \mathrm{S}$ e $\left.45^{\circ} 00^{\prime} \mathrm{W}\right)$.

Foi montada uma bancada de ensaio, constituída de caixas d'água, tubulações e medidores de vazão e de pressão (Figura 1). Utilizou-se de conjunto motobomba constituído de uma bomba marca FAL, modelo FM 0605, rotor fechado com diâmetro de $130 \mathrm{~mm}$, e motor elétrico WEG trifásico IP 55, de $5 \mathrm{cv}, 3.500 \mathrm{rpm}$, FS 1,15 e $60 \mathrm{~Hz}$. 
Os testes consistiram do levantamento das curvas características da bomba e potência demandada. Para os estudos sobre o desempenho da motobomba, o registro de gaveta, situado na saída da bomba, era gradativamente aberto, obtendo-se as seguintes medidas: pressão efetiva na entrada da bomba, por meio de um vacuômetro com coluna de mercúrio; pressão efetiva na saída da bomba por meio de um manômetro digital; corrente elétrica e voltagem em cada uma das fases, com uso de um alicate amperímetro; vazão utilizando placa de orifício, por meio da leitura da deflexão no manômetro diferencial do medidor, e velocidade de rotação, utilizando tacômetro digital.

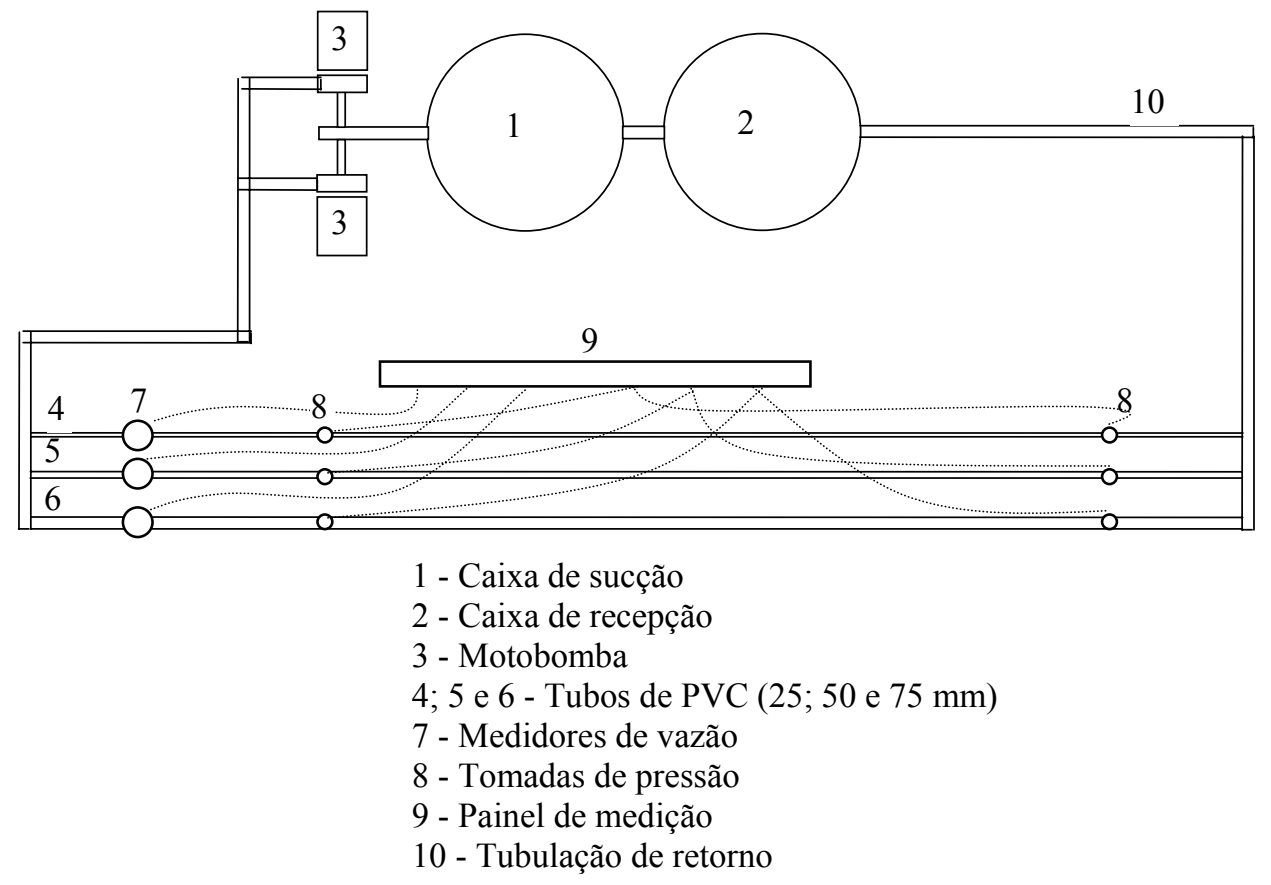

FIGURA 1. Esquema de montagem da bancada de ensaios. Sketch of bench test.

O percentual de carga sobre o motor elétrico foi estimado a partir da relação entre a corrente elétrica medida durante os ensaios e a corrente nominal $(100 \%$ de carga) para o motor elétrico utilizado (7,99 A - obtido em catálogo do fabricante). O rendimento (\%) do motor varia segundo a carga (\%) a que está submetido. A partir de valores de rendimento em função da carga, obtidos em catálogo do fabricante (WEG, 2006), foi ajustada a eq.(1):

$$
\eta_{M}(\%)=-0,0024 \mathrm{Ca}^{2}+0,452 \mathrm{Ca}+64,4
$$

em que,

$\eta_{\mathrm{M}}$ - rendimento do motor, $\%$, e

$\mathrm{Ca}-$ carga, $\%$.

O rendimento do sistema motobomba $\left(\eta_{M B}\right)$ foi obtido relacionando a potência útil $(\mathrm{Pu})$ com a potência ativa $(\mathrm{Pa})$, sendo as potências útil e ativa obtidas pelas eqs.(2) e (3):

$$
P_{U}=\frac{Q H_{\operatorname{man}}}{0,1019}
$$

em que,

$\mathrm{P}_{\mathrm{U}}$ - potência útil, $\mathrm{kW}$

$\mathrm{Q}$ - vazão, $\mathrm{m}^{3} \mathrm{~s}^{-1}$, e

$\mathrm{H}_{\text {man }}$ - altura manométrica, $\mathrm{m}$. 


$$
\mathrm{P}_{\mathrm{A}}=\frac{\sqrt{3} \mathrm{~T} \mathrm{i} \cos \varphi}{1.000}
$$

em que,

$\mathrm{P}_{\mathrm{A}}$ - potência ativa, $\mathrm{kW}$

T - tensão, volt;

i - corrente, ampére, e

$\cos \phi$ - fator de potência.

Para a obtenção do fator de potência $(\cos \phi)$ do motor, em função da carga (\%) a que está submetido, foi ajustada uma equação (eq.[4]) a partir de dados obtidos em catálogos do fabricante:

$$
\cos \varphi=0,26 \mathrm{Ca}+62,5
$$

De posse dos rendimentos do motor $\left(\eta_{M}\right)$ e do sistema $\left(\eta_{M B}\right)$, o rendimento da bomba $\left(\eta_{B}\right)$ foi dado pela eq.(5):

$$
\eta_{\mathrm{B}}=100 \frac{\eta_{\mathrm{MB}}}{\eta_{\mathrm{M}}}
$$

As curvas de desempenho da bomba, operando com água limpa e água residuária, foram corrigidas para rotação de 3.500 rpm, utilizando as eqs.(6) e (7) de Rateaux (CARVALHO, 2000):

$$
\begin{aligned}
& \frac{\mathrm{Q}_{1}}{\mathrm{Q}_{2}}=\frac{\mathrm{n}_{1}}{\mathrm{n}_{2}} \\
& \frac{\mathrm{H}_{1}}{\mathrm{H}_{2}}=\left(\frac{\mathrm{n}_{1}}{\mathrm{n}_{2}}\right)^{2}
\end{aligned}
$$

em que,

$\mathrm{Q}_{1}$ e $\mathrm{Q}_{2}$ - vazões para as rotações $\mathrm{n}_{1}$ e $\mathrm{n}_{2}=3.500 \mathrm{rpm}$, e

$\mathrm{H}_{1}$ e $\mathrm{H}_{2}$ - alturas manométricas para as rotações $\mathrm{n}_{1}$ e $\mathrm{n}_{2}$.

Foram utilizadas água pura e água residuária do processamento do café (descascamento e demucilagem). Inicialmente, foram obtidas as curvas de desempenho da motobomba do sistema (curvas Q x Hman; Q x Potência; Q x rendimento), no recalque de água pura, e depois com águas residuárias provenientes do descascamento e da demucilagem, e diluições dessas.

Os procedimentos descritos anteriormente foram repetidos para cada tipo de água residuária (demucilagem e descascamento) e para grau de diluição (3:1;2:1 e 1:1).

Amostras do fluido escoante foram coletadas na metade do tempo de cada ensaio, para a medição da temperatura, das análises físicas e químicas do fluido.

A massa específica de cada fluido estudado, bem como a concentração de sólidos totais (ST) e a concentração de sólidos voláteis foram determinadas no Laboratório de Análise de Água do Departamento de Engenharia - LAADEG/UFLA.

\section{RESULTADOS E DISCUSSÃO}

\section{Caracterização da água residuária}

$\mathrm{Na}$ Tabela 1, encontram-se as características dos fluidos utilizados (água residuária do descascamento e da demucilagem). Esses valores refletem os valores médios de amostragens obtidos ao longo dos ensaios com as águas residuárias. 
Observa-se, na Tabela 1, que a quantidade de sólidos totais presentes nas águas residuárias da demucilagem $(0,61 \%)$ e do descascamento $(1,09 \%)$ é considerada pequena, especialmente quando comparada às quantidades presentes em outras águas residuárias, como, por exemplo, no trabalho desenvolvido por SOCCOL (1996), em que a concentração do esterco suíno líquido variou entre $0,94 \%$ e $7,77 \%$.

TABELA 1. Concentração de sólidos totais $\left(\mathrm{mg} \mathrm{L}^{-1}\right)$, de sólidos voláteis $\left(\mathrm{mg} \mathrm{L}^{-1}\right)$ e massa específica $\left(\mathrm{g} \mathrm{cm}^{-3}\right)$ para as águas residuárias, descascamento e demucilagem do café, utilizadas nos ensaios. Total solids concentration $\left(\mathrm{mg} \mathrm{L}^{-1}\right)$, volatile solids concentration $\left(\mathrm{mg} \mathrm{L}^{-1}\right)$ and mass specific $\left(\mathrm{kg} \mathrm{m}^{-3}\right)$ for coffee process wastewater, utilized in the works.

\begin{tabular}{lccc}
\hline & Sólidos Totais & Sólidos Voláteis & Massa Específica \\
\cline { 2 - 4 } & $\mathrm{mg} \mathrm{L}^{-1}$ & $\mathrm{mg} \mathrm{L}^{-1}$ & $\mathrm{~kg} \mathrm{~m}^{-3}$ \\
\hline Demucilagem & 6.122 & 467 & 0,996 \\
Descascamento & 10.892 & 1.465 & 0,999 \\
Água destilada & - & - & 1,000 \\
\hline
\end{tabular}

A quantidade de sólidos voláteis, variando entre 7,6\% do total, para água de dumucilagem, e 13,8\%, para água de descascamento, pode apresentar diferenças no comportamento dessas águas residuárias como fluido escoante, com relação ao tempo. Entretanto, não foi objeto do presente trabalho fazer avaliação levando em consideração o tempo, o que, certamente, com a volatização, poderia alterar as características químicas e físicas, e, conseqüentemente, aquelas relativas ao escoamento.

Ainda na mesma tabela, os valores da massa específica das águas residuárias são inferiores ao da água, embora bastante próximos, resultando em diferenças menores que $0,5 \%$, sendo, portanto, de pouco efeito significativo no bombeamento. PERES \& SUZAKI (1988), embora tenham encontrado diferenças em torno de $1 \%$ entre a massa específica da água e da vinhaça, consideraram iguais para efeitos de bombeamento.

Embora não tenha sido medida, notou-se, pelo tato, aspecto pegajoso das águas residuárias, sendo mais pronunciado para água proveniente da demucilagem, caracterizando maior viscosidade.

Foram realizados ensaios hidráulicos utilizando água limpa, água residuária proveniente do descascamento e da demucilagem, com diluições dessas últimas. Assim, os fluidos utilizados nos ensaios, com as devidas concentrações, foram:

- Água limpa

- Água residuária do descascamento nas concentrações de sólidos totais de:

$1,09 \%$ (concentração original);

$0,82 \%$ (diluição na proporção de 3:1 de água);

$0,73 \%$ (diluição na proporção de $2: 1$ de água), e

0,54\% (diluição com 50\% de água, razão 1:1).

- Água residuária da demucilagem nas concentrações de sólidos totais de:

$0,61 \%$ (concentração original);

$0,46 \%$ (diluição na proporção de 3:1 de água);

$0,41 \%$ (diluição na proporção de $2: 1$ de água), e

0,31\% (diluição com 50\% de água, razão 1:1).

\section{Desempenho da bomba centrífuga}

Na Figura 2, são apresentadas as curvas de desempenho da bomba centrífuga operando com água, água residuária do descascamento e da demucilagem: (A) vazão x altura manométrica, (B) vazão x rendimento, e (C) vazão x potência demandada. 
Observa-se, na Figura 2A, diminuição do valor da altura manométrica quando o fluido escoante é a água residuária, sendo essa redução mais intensa para o bombeamento da água residuária proveniente da demucilagem. As águas residuárias, apesar de apresentarem valores de massas específicas próximos ao da água limpa, têm consistências mais viscosas, o que confere maior resistência ao escoamento, conseqüentemente, perda da capacidade da bomba no recalque de tais fluidos. No ponto de shutoff (vazão nula), as alturas manométricas foram diferentes para os fluidos analisados, sendo menor para a água e maior para água residuária de demucilagem.
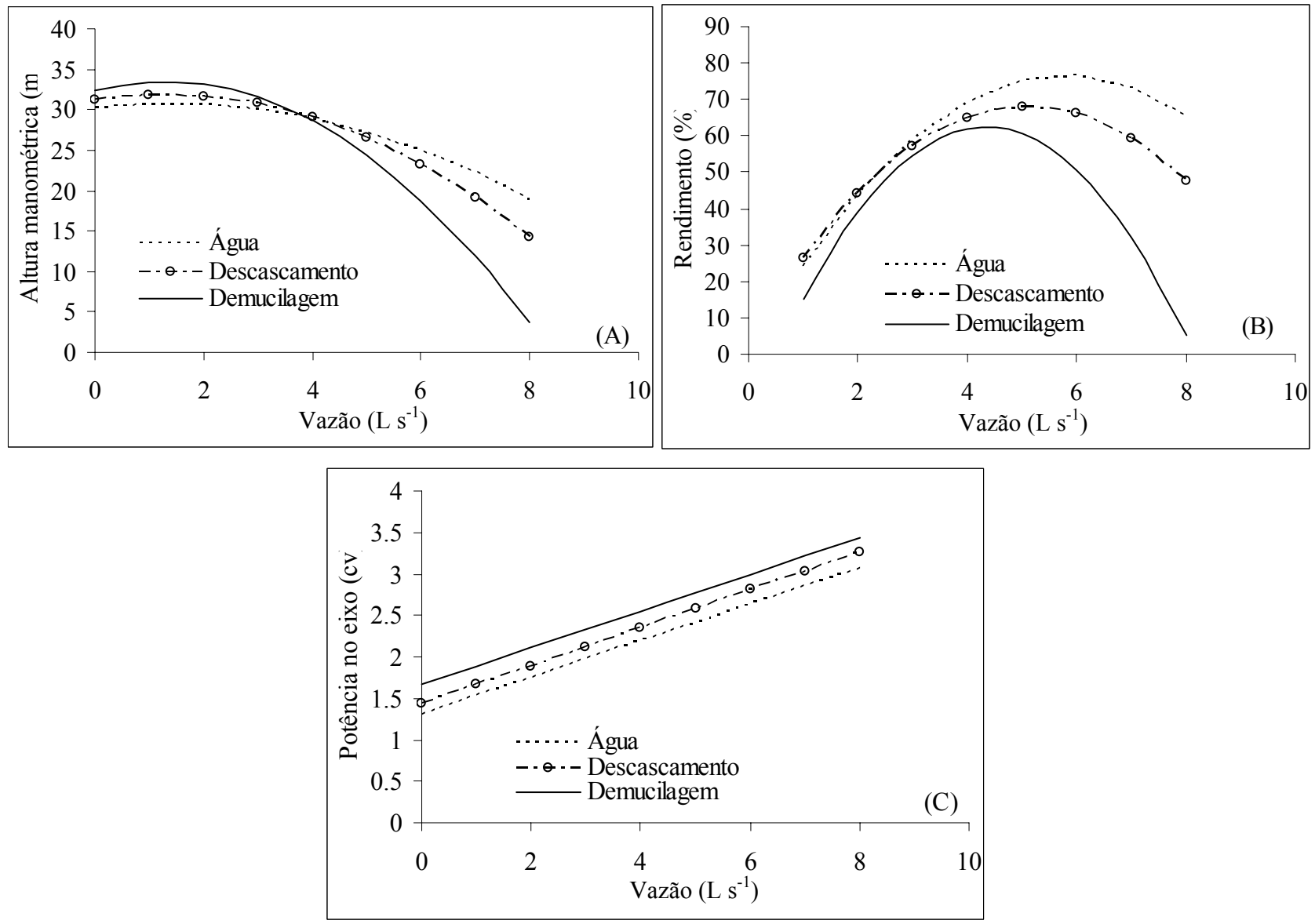

FIGURA 2. Curvas de desempenho da bomba (vazão x altura manométrica (A); vazão x rendimento (B), e vazão x potência (C)), operando com água, água residuária de descascamento e da demucilagem. Hydraulic characteristics of a centrifugal pump - discharge $\mathbf{x}$ manometric height (A), discharge $x$ efficiency (B) and discharge $x$ engine power (C), operating with clear water and coffee process wastewater.

Os testes foram repetidos e verificados os mesmos comportamentos, ou seja, diferentes alturas manométricas com o registro fechado. Provavelmente, os menores valores de massa específica desses fluidos, aliados à possível formação de bolhas (volatização de sólidos) podem ter contribuído para o aumento da altura manométrica. Com o aumento da vazão escoada, há inversão do comportamento da altura manométrica; nota-se maior queda da altura manométrica da bomba quando se recalca água de demucilagem, que tem aspecto mais viscoso que aquela advinda do processo de descascamento, oferecendo maior resistência ao seu deslocamento.

$\mathrm{Na}$ Figura 2B, em conseqüência da queda da altura manométrica, para o mesmo valor de vazão, há correspondente queda da eficiência, principalmente para vazões superiores a $4 \mathrm{~L} \mathrm{~s}^{-1}$. A diminuição da eficiência é crescente com a vazão, ou seja, quanto maior a vazão de recalque maior é a redução do rendimento, sendo mais acentuada quando se utiliza o bombeamento da água de demucilagem. 
Pela Figura 2C, observa-se aumento da potência demandada para qualquer valor de vazão quando se utilizam águas residuárias em comparação à água pura. Considerando o ponto de shutoff em que a vazão é zero, a potência demandada não é nula, pois o próprio giro do rotor dentro da bomba provoca atritos (mecânicos e hidráulicos), demandando potência. Quando se utilizam águas residuárias, essa demanda de potência é maior (maior viscosidade confere maior resistência ao escoamento e, conseqüentemente, maior demanda de energia). $\mathrm{O}$ aumento de vazão escoada aumenta as perdas internas e, conseqüentemente, reduz a altura manométrica (isto ocorre com maior magnitude quando o fluido bombeado possui maior viscosidade e/ou massa específica; neste trabalho, as águas residuárias apresentaram, pelo tato, aspecto mais viscoso). Como conseqüência da redução da altura manométrica e do rendimento, a potência, para um mesmo valor de vazão aumenta (Figura 2C). Considerando o mesmo valor de vazão, a potência demandada cresce na seguinte ordem: água limpa, água residuária do descascamento e água residuária da demucilagem.

Considerando os resultados (curvas de desempenho) apresentados, a utilização de bomba centrífuga comum (rotor fechado) para o recalque dessas águas residuárias (provenientes do processo de descascamento e de demucilagem) resulta em diminuição da capacidade dessas, com redução da pressão e de rendimento, com conseqüente aumento da potência demandada.

Normalmente, a bomba centrífuga com rotor fechado é mais comumente encontrada e disponibilizada em uma propriedade agrícola. O uso desse tipo de bomba para o recalque de água residuária do processamento do café poderá ser feito aproveitando-se o uso de bombas já existentes na propriedade. Nesse caso, é importante levar em consideração, para o dimensionamento de sistemas, a redução no desempenho desse tipo de bomba.

$\mathrm{Na}$ Figura 3, são apresentadas as variações (\%) da altura manométrica (A), do rendimento (B) e da potência demandada $(\mathrm{C})$, para cada um dos fluidos escoantes (descascamento e demucilagem) em relação ao desempenho da mesma bomba operando com água limpa. Na Figura 3A, observa-se que, para vazão de até $50 \%$ da vazão total da bomba, o desempenho (vazão x altura manométrica) foi semelhante, com ligeiro aumento da altura manométrica quando se utilizou água residuária. A partir de 50\% da vazão nominal, há redução da altura manométrica com a vazão, sendo maior para água de demucilagem, atingindo quedas de até $80 \%$ para vazão próxima da nominal da bomba.

Na Figura 3B, observa-se a diminuição do rendimento, atingindo quedas de até quase $100 \%$ quando a vazão atinge o valor nominal. Também, aqui, maiores quedas foram observadas para a água de demucilagem. Em conseqüência das reduções da altura manométrica e do rendimento com a vazão, a potência demandada aumenta (Figura 3C). Observa-se que o aumento da potência é maior para água de demucilagem; para o ponto de shutoff, o aumento chega a $26 \%$ e $10 \%$ para águas de demucilagem e de descascamento, respectivamente. É importante ressaltar que, nesse ponto, houve aumento da altura manométrica desenvolvida quando o líquido era água residuária (descacamento ou de demucilagem). À medida que aumenta a vazão, o aumento da potência varia inversamente, ficando entre 5 e 10\% para água de descascamento e entre 15 e 26\% para a demucilagem. Baseado nesse comportamento, o aumento da potência em torno de $10 \%$, como preconizado na literatura para o recalque de outros fluidos residuários, ou mesmo $20 \%$ como preconizado por SOCCOL (1996) para água residuária da suinocultura, pode ser insuficiente quando se trata de água residuária da demucilagem do café. Já, a margem de segurança sugerida por MACYNTIRE (1987), de 30\% do valor da potência para o bombeamento de misturas líquidosólido, é bastante próxima ao aumento verificado para a demanda de potência com o uso da água de demucilagem, e excessiva quando se utiliza água de descascamento. 

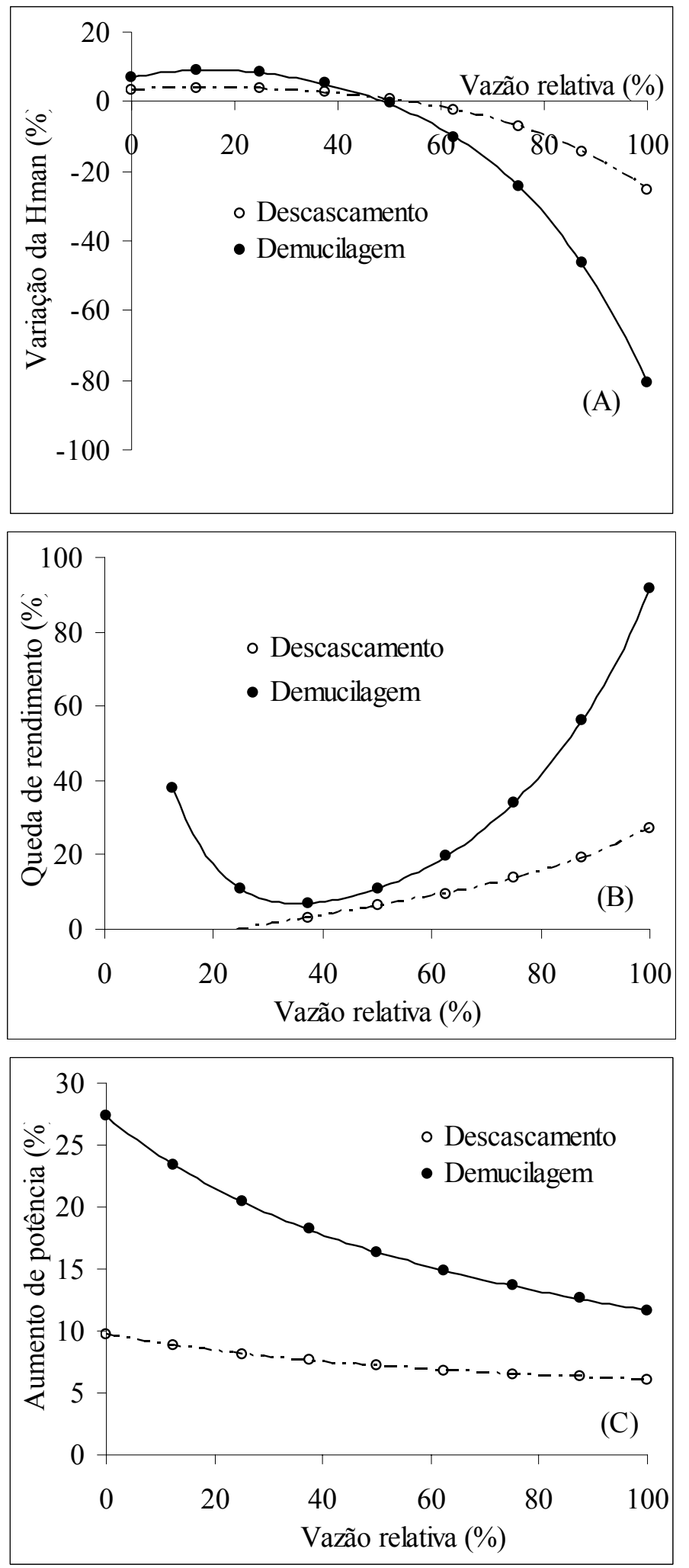

FIGURA 3. Variação da altura manométrica (A), queda de rendimento (B) e aumento da potência (C), em função da vazão, para a bomba operando com água residuária de descascamento e de demucilagm em relação ao desempenho com água limpa. Variation of manometric height (A), decrease of efficiency (B) and increase of engine power (C), as a function of discharge, of a centrifugal pump operating with wastewater from coffee process in comparison with results obtained for water. 
Observa-se que, pela Figura 3, ocorreram quedas da altura manométrica e do rendimento, crescentes com a vazão, notadamente a partir de $50 \%$ da vazão nominal, enquanto a demanda de potência, embora tenha aumentado, não foi proporcional à vazão, ou seja, maiores aumentos da potência foram observados para menores valores de vazão. Deve-se lembrar que a potência é função direta da altura manométrica (portanto, diminuição dessa reduziria a potência), e inversamente proporcional ao rendimento da bomba (redução no rendimento causaria aumento da potência demandada). Isso justifica, então, menor aumento da potência com a vazão.

É importante ressaltar que, neste trabalho, utilizou-se de bomba centrífuga de rotor fechado, sendo o tipo mais comum de bomba utilizada nas propriedades agrícolas. Embora os resultados não tenham apontado nenhuma irregularidade de funcionamento da bomba com os fluidos utilizados, é importante que novos trabalhos possam ser realizados com outros tipos de bombas (rotores abertos e semi-abertos) e com outras bombas de rotores fechados, mas com diferentes espessuras entre discos (espessuras das pás).

\section{CONCLUSÕES}

A bomba centrífuga operando com água residuária da demucilagem do café apresentou desempenho inferior àquele obtido com água residuária do descascamento, mesmo apresentando menor concentração de sólidos totais.

A bomba centrífuga operando com água residuária (descascamento e demucilagem) do processamento de café apresentou redução da altura manométrica e do rendimento, em relação aos valores obtidos com água limpa, principalmente para vazões acima de 50\% da vazão nominal.

A potência demandada para a mesma vazão cresce na ordem: água limpa, água residuária do descascamento e água residuária da demucilagem.

\section{REFERÊNCIAS}

CAMPOS, C. M. M.; CARMO, A. C. do.; LUIZ, F. A. R. de. Impacto ambiental causado pela poluição hídrica proveniente do processamento úmido do café. Revista Cafeicultura, 2003. Disponível em: http://www.arvore.com.br/artigos/htm_2003/ar3001_2.htm. Acesso em: 9 mar. 2007.

CARVALHO, J.A. Dinâmica dos fluidos e hidráulica. Lavras: UFLA, 2000. 230 p. Apostila

MACYNTIRE, A.J. Bomba e instalações de bombeamento. Rio de Janeiro: Guanabara Dois, 1987. $667 \mathrm{p}$.

PERES, J.G.; SUZAKI, S. Bombeamento de vinhaça: um estudo sobre perda de carga. Brasil Açucareiro, Rio de Janeiro, v.106, n.3, p. 2-8, 1988.

SOCCOL, J.O. Desempenho de bomba centrifuga operando com esterco suíno líquido. 1996. $70 \mathrm{f}$. Dissertação (Mestrado em Irrigação e Drenagem) - Universidade Federal de Viçosa, Viçosa - MG, 1996.

TEIXEIRA, H.A. Influência da concentração de areia nas curvas características das bombas centrífugas. 1973. 44 f. Dissertação (Mestrado em Engenharia Civil) - Escola de Engenharia de São Carlos, Universidade de São Paulo, São Carlos, 1973.

WEG. Catálogo eletrônico de produtos. Jaraguá do Sul, 2006. Disponível em: http://www.weg.com.br. Acesso em: 15 ago. 2007. 